\title{
A place for sharing: The emotional geographies of peer-sharing in UK University halls of residences
}

\section{Holton, DM}

http://hdl.handle.net/10026.1/8094

\author{
10.1016/j.emospa.2016.11.003 \\ Emotion, Space and Society \\ Elsevier BV
}

All content in PEARL is protected by copyright law. Author manuscripts are made available in accordance with publisher policies. Please cite only the published version using the details provided on the item record or document. In the absence of an open licence (e.g. Creative Commons), permissions for further reuse of content should be sought from the publisher or author. 
"This is the author's accepted manuscript. The final published version of this work (the version of record) is published by Elsevier in Emotion, Space and Society 1 1st February 2017 available at: 10.1016/j.emospa.2016.11.003. This work is made available online in accordance with the publisher's policies. Please refer to any applicable terms of use of the publisher."

\section{A place for sharing: the emotional geographies of peer-sharing in UK university halls of residences}

Holton, Mark (2017) - School of Geography, Earth, and Environmental Sciences, Plymouth University

Accepted - 8 November 2016 (embargo until 8 May 2018)

Cite this article: Holton, M. (2017). A place for sharing: The emotional geographies of peer-sharing in UK University halls of residences. Emotion, Space and Society, 22, 4-12.

\section{Abstract}

Our homes are important spaces through which emotions are produced, performed and regulated. They carry significant material and symbolic value and are inscribed with meaning and belonging that are often crucial in shaping and (re)producing collective and individual identities. Yet while research has explored the role of the home in the co-production of familial values, networks and behaviours, less is understood of the emotional geographies of accommodation occupied by non-related adults - defined here as 'peer-sharing'. This paper responds to this gap by exploring how peer-shared living-spaces are emotionally constructed through a case study of 
students living in a UK university's halls of residences. In doing so, this paper examines how (1) the morphology of shared living-spaces contributes towards the production of sharers' emotions, (2) emotions become inscribed upon home-spaces through place-making activities and (3) diversity is enacted through the emotional work of sharers and how this is performed through friendship in shared living-spaces. This analysis concludes by emphasising the important role of emotions in coproducing different spaces, activities, knowledges and experiences among peersharers and how peer-sharing might be both performed in and influenced by living spaces.

\section{Keywords}

Student geographies, halls of residence, first year students, emotional geographies, peer-sharing.

\section{Introduction}

Since the 'affective turn' in the social sciences in the 1990s (Clough and Halley, 2007) research has grappled with the complexities of emotions, exploring how our embodied experiences and feelings influence our interactions with(in) certain spatial scales (Anderson and Smith, 2001; Davidson et al., 2007). Davidson and Milligan (2004: 523) have seminally argued that: "emotions [...] take place within and around [the] closest of spatial scales", providing geographical contexts that may enable understandings of the relative associations between potentially contrasting emotional behaviours. Moreover, while emotions may be in and of the body, they equate to more than simply cause and 'affect' and can influence experiences of environments both spatially and temporally (Brown, 2011). There is a well-established body of work that examines the role of emotions in home-spaces (Blunt, 2005; Hockey et al., 
2007). Yet, while our homes are recognised as important sites through which emotional work is produced, performed and regulated, such research has engaged less with the emotional geographies of accommodation occupied by non-related adults - defined here as 'peer-shared households' (Heath, 2004). Rates of peersharing among young people are increasing (Clapham et al., 2014; Moos, 2015) due to competitive rental markets (Van Criekingen, 2010) and a growing reliance upon multiple incomes to subsidise rents (Smith, 2012). Yet, little has been discussed of how young adults might perform peer-sharing in their accommodation and how this might influence their shared living experiences. Following Pile's (2010) call for emotional geographers to investigate the 'spaces in-between' to explore how emotions produce, or are produced by spaces, this paper examines how the emotional construction of the shared non-familial home informs different spaces, activities, knowledges and experiences among peer-sharers.

As Blunt (2005) posits, our homes carry significant material and symbolic value, they are inscribed with meaning and with belonging and are often crucial in shaping and (re)producing collective and individual identities. Crucially, we dwell within our homes and for those living in temporary, short-term or shared accommodation, dwelling may well be part of a more complex process of mobility - a stop, a pause or a break in proceedings. Indeed, Heidegger (2011) instructs that "dwelling is the manner in which mortals are on the earth" (245), insofar as to dwell is to consider the performance of an activity in conjunction with other activities - "we work here and dwell there" (Heidegger, 2011: 245, emphasis my own). Moreover, notions of 'travelling-in-dwelling' and 'dwelling-in-travelling' have been developed by Clarke (2005) to emphasise how home, for those on the move, hinges on the interplay between the moveable and the stuck, the material and the symbolic, the corporeal 
and the imagined. Yet while this may emphasise complexities in how people reside together, what is often missing is an understanding of how sharing might produce, or be produced by, different emotional factors for those in transition. For instance, Giorgi and Fasulo (2013) draw upon the term 'global abode' to refer to "a notion of home captured in the tension between mobility and stasis" (113). They argue that such tension can be partly ameliorated through the transportation of material objects that may produce familiarity, maintain imagined connections and provide a sense of home while in transition, something that will be attended to in this paper. To explore these phenomena, this paper examines how (1) home-spaces produce emotions through their morphology, (2) emotions become inscribed upon home-spaces through place-making activities and (3) diversity is enacted through the emotional work of sharers and how this is performed through friendship in shared living spaces.

\section{Peer-sharing and friendship}

Research suggests that interactions within households have adapted in line with changes to our contemporary (im)mobilities, labour structures and access to technology (McDowell, 2007). Propinquity has become less important within the post-modern home with a growing tendency for connections between householders to be structured more by ephemeral bonds than strong familial networks (Moos, 2015; Clapham et al., 2014). As McDowell (2007) argues: "the home increasingly is a space marked by [...] the co-presence of people united not by ties of blood and affection but by economic exchange" (130) and this caution is perhaps essential in informing the complex, non-familial ways of contemporary living outlined in this paper. Williams (2005), for example, discusses how non-familial co-housing may facilitate transferences of social capital among cohabiters that provide the building 
blocks of community cohesion. Other more heteronormative understandings of interpersonal relationships within the home have been subverted to emphasise the diverse ways unrelated adults might experience a sense of 'at-homeness' in shared accommodation (Wilkinson, 2014). Moreover, Kenyon and Heath (2001) touch upon the non-material benefits young people might draw from shared living arrangements such as the trade-off between company and privacy which may not be so easily negotiated in coupled or familial relationships (Heath and Kenyon, 2001). Furthermore, Jarvis (2011) argues against proximity and social interaction as being the sole proponents of convivial co-resident accommodation, proposing instead that harmonious and sustainable living also includes carefully cultivated time-space negotiations within households and between sharers. For example, Moss and Richter (2010) suggest that daily routines may not have clear spatial or temporal organisation in shared living spaces, with activities being performed in the same environment, and at different times of the day, offering little opportunity for differentiation or structure. What punctuates these debates though is how the individualisation of identity, or a conflation of the Self, has become synonymous with peer-sharing. Here, researchers have typically drawn upon Giddens' (1991), Beck's (1992) and Bourdieu's (1984) views on post-modern lifestyles (especially among young people) as being developed through self-identity, independence, risk and choice. Hence, we approach our lives self-reflexively, intensely scrutinising, monitoring, (re)evaluating and (re)configuring our identities according to our own "project[s] of self-identity" (Reimer and Leslie, 2004: 191). Crucially, this paper extends the influences of individuality upon peer-sharing and how this facilitates interactions in contemporary accommodation. Where some types of shared accommodation might provide fairly soft structural regulation (Moss and Richter, 
2008) there remain ample opportunities to explore how such spaces may affect the emotional relationships that are negotiated between sharers.

Moreover, friendship is crucial in developing meaningful and lasting interactions in shared living arrangements. The context of peer-sharing encourages new ways of considering and understanding friendship by examining the contrasting ways in which friendships are produced, performed and negotiated through shared interactions. Bowlby (2011) argues that friendship "is a key aspect of patterns of sociability [that recognises] (or not) solidarities and communal belonging" (605). Friendships are commonly built upon trust, activity and communication and the common practices this produces among friendship groups. Yet friendship networks are complex and their fluid, temporal, and sometimes ephemeral, qualities make them difficult to spatially contain (Bunnell et al., 2012). As this paper suggests, friendships can also be paradoxical, shifting between being proximate or virtual, firm or ephemeral, present or disembodied, emotional or material. This paper responds to Bunnell et al.'s (2012) call for more critical investigations of the "formation, significance and spatiality" (500) that constitute young people's geographies of friendship. For example, in the context of student friendships, Robertson (2016) argues that friendship is a vital component in the production of 'translocal subjectivities' (Conradson and McKay, 2007) for those in mobility as they interact (with)in new social and living environments. Notwithstanding, friendships are intrinsically tied to relationships with place and processes of place-making and the ability to enact social identities among 'people like us' (Fincher and Shaw, 2009).

\section{Accommodating students}


To examine the emotional relationships between sharers this paper draws upon a case study of UK university students living in Plymouth University's halls of residences (hereafter referred to as halls). Student halls are particularly useful in understanding the complexity of sharing as they are usually occupied by groups of young, mobile, disconnected people who are mostly embarking on their first experiences of living away from home. Friendship and living arrangements are thought to be crucial components for sojourners' (re)adjustment and emotional wellbeing (Brown, 2009). Hence, this provides an insight into how emotional work might influence, and be influenced by, temporary residents and how this may challenge some of the ways in which we think about the occupation of 'home-spaces'. Accommodation has been central to discussions of the geographies of students for centuries. Historically, institutions have provided halls in some shape or form to students (Blakely, 1994; Silver, 2004). The Oxbridge college model has, since its inception, acted in loco parentis (Morgan and McDowell, 1979) as surrogate parents, harnessing academic reflection not clouded by domestic responsibilities. From the $19^{\text {th }}$ century the new civic universities that were formed as urban home-based centres of learning contrasted with the seemingly 'detached' Oxbridge models. These more 'local' institutions were designed without accommodation in mind, instead encouraging learners to remain at home during their education. This, inevitably, did not last with universities recognising the need to accommodate students and by the 1960s student halls had become a ubiquitous feature of HE locations (Holdsworth, 2009; Silver, 2004). This, coupled with the opening of post1992 universities and the rapid influx of students, contributed to the familiar patterns of home-to-halls-to-rented housing recognised today in most university towns and cities (Smith, 2008). Nevertheless, this is changing again through the 
neoliberalisation of the HE sector that has seen funding stripped away from accommodation and provisions sub-contracted out to private companies that build, maintain and even manage their own purpose built student accommodation (PBSA) (Smith and Hubbard, 2014). This has created mixed provisions of accommodation for university students in terms of quality (modern/dated), availability, infrastructure (service/facility provisions), management (university/private), and location (on/offcampus). Yet while halls living remains the accepted route for most students into their first year of study, recent figures demonstrate that considerable stress has been placed upon availability with just 359,520 bed-spaces available for 502,230 first year undergraduates in 2013/14 (Higher Education Statistics Agency (HESA) 2016). Such inequalities in the accessibility of bed-spaces has seen university managed and private hall bed-spaces increase by 48,915 between $2007 / 08$ and 2013/14 with large scale accommodation projects becoming commonplace in many university locations ${ }^{1}$.

Moreover, contemporary research has sought to interrogate UK students' 'housing biographies' further (Holton, 2016a; 2016b; Rugg et al., 2004) by investigating the heterogeneity of undergraduates and how this problematises many of the structures placed within the university campus (Andersson et al., 2012; Hopkins, 2011). For example, previous work has examined halls in terms of ethnic and gendered (Andersson et al., 2012), sexual (Taulke-Johnson, 2010) and (inter)national (Fincher and Shaw, 2009) diversities, emphasising the difficulties faced by sharers in negotiating the social, and at times structural, inequalities found in halls spaces. This is particularly prescient in light of some of the hegemonic and heteronormative

\footnotetext{
${ }^{1}$ Plymouth University attracts the amongst the largest number of first year undergraduates of all UK Universities (HESA, 2016)
} 
behaviours that have been identified in UK halls and how this has instigated further separations and segregations based upon the premise of ameliorating prejudice and victimisation (see The Guardian (2016) for a discussion of The University of Birmingham's LGBT-only halls). Such work points to halls as playing a prominent role in the term-time experiences of students (Christie at al., 2002). Yet, while the literature recognises the diverse social interactions mentioned above, so far, little has been discussed of how the materiality of the halls themselves might shape students' interactions with(in) them. This paper examines how the emotional interplay between the morphology of the hall, the place-making activities present in halls and the diversity of those sharing in halls contribute towards developing meaningful and sustainable friendships and convivial shared living.

\section{Methodology}

This research was conducted in the spring of 2016 with fifteen students from Plymouth University ${ }^{2}$ who were living in university-managed halls. The data were collected through a series of in-depth semi-structured, place-based interviews that were conducted in the students' kitchens to encourage them to engage directly (and critically) with their surroundings. Interviewing the students in place was a key component of this research and exposed the complex ways in which shared and private spaces were utilised by flatmates. Being present in the halls spaces meant that the interview sites were more than places of convenience, encouraging the participants to consider the relationships between the different spaces within their

\footnotetext{
${ }^{2}$ Plymouth University presents itself as an interesting location for studying experiences of halls of residences as it has the sixth highest concentration of undergraduates $(24,675)$ and among the highest first year intake (7,655 in 2012/13) in the UK (HESA, 2016). Plymouth contains several large and small scale student halls which comprise a mixture of University and privately managed properties totalling 4000 bed spaces with another 1500 bed spaces approved for construction.
} 
halls and their interactions within them. Elwood and Martin (2000) suggest that this type of interview methodology is conducive to revealing the spatial relations and meanings which constitute the 'micro-geographies' of place as well as uncovering the power dynamics associated with(in) place(s). In relation to students, Holton and Riley (2014) argue that place-based encounters usefully combine the verbal with the visual and stimulate critical engagement with environments. These interviews therefore facilitated discussions that teased out the subtle differences between the uses of halls spaces. A research diary was also kept to detail the observational and non-verbal characteristics of each encounter, extracts of which are used in the analysis. Alongside the interview responses and observations, photographs were taken of the students' communal spaces (kitchens, corridors and common rooms) during and after the conversation. The participants were invited to take and/or direct the photography and this presented some opportunities to gain more insight into their flats as well as allowing the participants to provide more contextual detail to their own responses. Crucially, these images produced by the students, while providing an interpretive, and somewhat comparative, research tool, carried their own agency (Rose, 2016). It would be problematic to assume these as entirely 'natural' scenes and their framing may expose or hide particular details. Hence building upon Pinney's (2004) caution that images are neither inert nor true, it was important to use these photographs not just as visual depictions of 'reality' but to consider them in conjunction with the interview transcripts and observations to understand their potentially conflicting (inter)relations, (re)production and power. This 'layering' of methods helped deepen the dataset, allowing for a much richer analysis than the verbal responses alone could provide. 
The demographic breakdown of the sample was balanced by gender with seven males and six females but showed a leaning towards the students being young (14), White (14) and British (12). This is not particularly unusual in the UK context as most residents in halls are likely to be first year students who have come to university straight from A-Levels (Christie et al., 2002). With regard to the composition of the students' flats, each contained a potentially diverse mixture of gender, sexuality, ethnicity and nationality. Plymouth University operates a system whereby students complete a personality survey before making their choices in order to determine their living preferences (e.g. the types of people they like to socialise with, times of day they socialise, the activities they enjoy etc.). The results of these surveys, while not entirely rigorous (young people's identities are, of course, not fixed), present some opportunities for students to mix with people based more upon personality traits than siloing them according to demographics.

\section{Emotional materialities}

One of the important themes that emerged from the analysis was how the participants' experiences of living together were differentiated through the materiality of the spaces in which they inhabited. The style, form and layout of the halls were key contributing factors in how the sharers formed, articulated and performed friendships in and through their flats. The mixed provisions of halls in university locations also meant the students were likely to interact differently with a hall depending on its age, condition and proximity to other spaces. This was expressed by Adam and Nina, both students living in the same flat in one of the modern privately managed halls within Plymouth, and by John who was living in a block erected in 1990s adjacent to the campus: 
Nina: "The layout of our flat means we can socialise really easily. I mean we are closer than most halls to the bars so pre-drinking often starts here."

Adam: "Yeah, the layout of the halls is so different, I mean we've got a HUGE sofa and my mates are so jealous of it [...]!"

Nina: "Yeah, I'm so pleased we got this flat, I mean, I love my room but, you know my parents are even jealous of our kitchen! It's really communal and people feel part of the conversation if they are cooking, watching TV or studying."

"I was a bit disappointed in the basic facilities in the kitchen as I'm really techy and into my cooking - like last week I cooked us all a stir fry. Mostly we tend to cook in the kitchen and then eat in our rooms though. There's nowhere for us to get comfortable, not like some of the other flats I looked at - gutted eh?! (laughs)." (John)

Following Pile's (2012) suggestion that emotional geographies value the interweaving of "proximity, intimacy and closeness" (16), these comments emphasise how the morphological configuration of each flat became central to the interactions that occurred within it. While the proximity of the sharers meant interactions were largely inevitable, the quality of these interactions was highly dependent on the types of activities they could perform within their flat. Here, the capacity for friendship networks to form within the flat depended on a range of structural factors (access to functioning communal space, the provision of shared facilities and a shared desire to interact with these facilities in complimentary ways). As the participants' rather emotive comments suggest, the ability to make the right types of quality connections was essential in maintaining cohesive, reciprocal 
relationships in the communal spaces of their flats. While our homes are most appropriately read at the local scale (Dyck, 2005), this analysis suggests that peershared homes can take on multiple and finely-graded layers of the local through which emotions are articulated (in this case through (or not) conviviality, sharing and friendship). As Blunt and Dowling (2006) argue, "households are not bounded units but, rather, their 'members' survival and well-being is also influenced by their connections with other households - kin, friends or neighbours" (80). Indeed, these very local relationships are highly influential in successful sharing but as the comments suggest, there are incongruities between the quality of interactions anticipated in the home and the spaces that are available to interact in.

Beyond appraising how the structuring of halls shaped the social interactions that were performed within them, Robert's experience below indicates how the layout of his flat directly affected his privacy:

"It's a bit weird having a balcony backing on to your room but it's okay. That's my room there [points], through the window. It gets a bit awkward if the curtains are open because, well, you know, you can see everything in my room! [...] I bought this curtain because if you're in the corridor you can see right through into my room which really isn't very private." (Robert)

In terms of how emotions co-produce the 'space in-between' (Pile, 2010), Robert's encounter(s) with his living space were anything but smooth. His example (Figure 1) paradoxically blurs and challenges the boundaries of what might described the 'frontand-back-of-house' boundaries (Boon, 2007; Goffman, 1959) of the peer-shared home, particularly through the ways in which identities are produced, performed and negotiated within them. While many of the participants mentioned carefully 
negotiating how use of the shared spaces might be interpreted (e.g. through implementing house rules or the screening of guests), the permeability of the balcony disrupted this for Robert, placing his room on show. Robert's flat was unusual in having clear glass balcony doors and the other flats that were visited in this hall had frosted panels to screen the adjoining bedrooms (Figure 1):

"It can be quite annoying when you are sitting in your room and someone opens the balcony door up and fills your room with cooking smells. [...] It's funny really, I feel like if I want to make a private phone call I'll go out - I never bring friends back into my room. It feels really weird." (Robert)

\section{[Insert Figure 1 here]}

Bowlby (2011) suggests that inviting people into the home can be an intimate process in which guests may be privileged certain insights into the 'private self'. While almost all of the participants spoke of having the option to retreat to their bedrooms when guests were over, Robert felt his privacy was compromised - even though, when closed, the windows and curtains perhaps offered him no less privacy than his fellow flatmates had. For him, having a window that looked directly into his room from the kitchen felt akin to inviting strangers into the intimacy of his bedroom, contradicting perhaps how the shared spaces of the flat might be framed. Robert's experience of emotional corporeality amplifies Búriková's (2006) "embarrassment of co-presence" (118), whereby sharers retreat into the solitude of the bedroom, particularly if privacy appears compromised. But there is more than just bodywork at play here. From Adam and Nina boasting of their 'social hub' to John's disappointment with his shared facilities to Robert's concerns over privacy that pushed him away from his flat. Following Davidson and Milligan (2004), what this 
demonstrates is how the complex interplay between emotions, bodies and spaces can be accomplished both individually and collectively, co-producing different forms of interaction, and at times regulation, among peer-sharers.

\section{Emotional place-making}

Beyond the layout of the halls, the students' shared spaces were quite literally adorned with emotions through various place-making activities. While decorating flats was forbidden there were often small forms of resistance that were performed in the communal spaces. The placement of temporary items propped against walls, personal notes pinned to the fronts of fridges and festive decorations stuck to ceilings, windows and walls all indicated that the shared spaces the students occupied were more than simply communal but had an emotional-presence actively inscribed into them:

"We use the noticeboard as a way of personalising the kitchen, I mean you can't stick stuff on the walls so it's hard. You can make it yours though. It's nice to draw pictures and messages to each other." (Grace)

“The pictures up there are a nice way of personalising the kitchen, we're doing our best to make it a bit more homely". (Peter)

"We use those [fridge] magnets to write stupid messages to each other. God knows what the cleaner must think!" (Sophie)

These ludic activities mentioned here lend a more personal and dynamic quality to the shared spaces that belie their institutionalness and instead promote homeliness. This suggests that halls are more than simply functional spaces. As Reimer and Leslie (2004) argue, interactions with the material items within the home are 
subjective, producing emotional attachments to items that contribute to the making of place. Figure 2 show the noticeboards in Peter's and Gary's kitchens and depict some of the ways in which the flatmates articulated fun, friendship and togetherness in their kitchens. In Gary's case:

"The [kitchen] contained a very large whiteboard which the flatmates had covered with drawings, notes and pictures. There were takeaway menus stuck to it and some of the rules and regulations for conduct in the halls. This was quite an important feature for Gary and he boasted that they were lucky as other flats only had pin-boards. There was evidence of the flatmates sharing the space, with a few text books and novels left of the table and a couple of canisters of sweets which Gary said were for everyone." (Research diary)

[Insert Figure 2 here]

This extract, along with the images and comments above, indicate the ease with which these flatmates lived among one another. The articulation of language, humour and intimacy, the development and expression of memories, the sharing of experiences, all appear to contribute towards a more convivial 'sensing' of place and of belonging within peer-shared homes. Peter's flat, for example, had put together a menu of recipes that each of the flatmates could cook and shared that on their noticeboard. This demonstrates that the temporary application of these fleetingly emotional personal items made these short-term peer-shared living environments simultaneously functional and evolving spaces. Here, relationships that were developed through a constellation of shared encounters in the flats emphasised that, while they were unable to formally make material adjustments to their communal 
spaces, by investing in emotional capital they demonstrated a keenness to 'make it theirs' for the short time they were living there (Holton and Riley, 2016). Silva (2007) defines emotional capital as the "capacity to connect, involving acts, intentions and sentiments [...] about personal connections and intimate life" (145). Hence, the emotional exchanges that were present in the shared flats were inscribed directly into the materiality of the home, both in a literal sense through the functionality and usability of the spaces but also through the imaginative and creative use of items as communicative devices. As Watkins (2006) suggests, kitchens and their constituent parts (fridges, cupboard doors, windows etc.) may be repurposed beyond their functionality "as site(s) for information exchange and creative self-expression" (148). From the photographs of friends pinned to Peter's noticeboard, the cartoons and doodled messages left by guests on Gary's white board (Figure 2) and the arrangements of 'word' magnets on Sophie's fridge, these emotional and collective forms of place-making made the communal spaces intensely dynamic through the agency of the sharers.

Moreover, personalising was more than simply place-making. The emotional work the students invested into their flats was at times expressed through some rather oblique cultural references that were written into the communal spaces:

"You want to enjoy the space. It's not a production line, we live here. We want people to see our little marks in here. How we've made it our own. We went out and bought those Christmas decorations on the window and put them up to make it look nice. We've left them up as a bit of a joke." (Scott) 
"You won't get this, but all the spiders [stuck around the kitchen] are called

Phillip. We have little details and little quirks and everyone's just kind of stuck to it." (Ben)

Scott and Ben's comments (Figure 3) extend notions of emotions being about the Self by indicating emotionally intense, inclusive, yet distinctive, methods of placemaking that could be construed as galvanising the group's collective identity. Indeed, their comments emphasise their shared identities as simultaneously embodied and social and expressed through their emotional place-making performances in their flats. These forms of collective self-expression are essential for sharers in transition whose mobility makes developing transitory identities complex and uncertain. Urry (2002) talks of occasional co-presence being essential for those in mobility - those corporeal or bodily attachments to people assist greatly with anchoring to temporary places for those in mobility (Gustafson, 2001). Put bluntly, our expectation for presence and attention mean we are often socially obliged to make meaningful proximate, corporeal social interactions in order to build trusting relationships (Urry, 2003) and the peer-shared hall is one such location where the emotional intensity of these interactions is writ large. This can be understood through the more emotional qualities of friendship among the sharers. As Brooks (2007) suggests, halls can be key sites in which new identities are produced and chance friendships developed among peer-sharers. This is exemplified through the emotional place-making activities described by the participants above that draw flatmates together through shared experiences and emotional connections. This makes Robertson's (2016) caution against labelling students as "simply transient sojourner-consumers" (13) all the more prescient, particularly as many of the emotions connected to students' initial experiences of university (excitement/fear, assurance/trepidation, unease/calm 
etc.) can be spatially and temporally located in, and articulated through, their accommodation. This was demonstrated in the ways in which emotions were actively inscribed within the shared spaces through the placement of belongings and/or use of noticeboards to communicate and this tells us much about the quality of friendship and cohabitation for those living in temporary peer-shared spaces.

\section{[Insert Figure 3 here]}

\section{Emotional diversity}

A final important observation of the emotional work within peer-shared halls was the multiple configurations of culture, gender and age within the shared flats. Andersson et al. (2012) discuss the implications involved in mixing students together in halls, particularly in terms of how 'throwntogetherness' (Massey, 2005) does not necessarily equate to successful interactions. Indeed, while Massey (2005) suggests that "place is an ever-shifting constellation of trajectories [that] may set us down next to the unexpected neighbour" (151), these unforeseen encounters are not necessarily harmonious. Valentine (2008) talks of how the geographies of encounter can shape interactions and understandings of difference and in terms of the emotional characteristics of peer-sharing, this could serve to reinforce, rather than mitigate inequalities. Amin (2002) cautions that such hegemonic identities emphasise the politics of place through which the "the micropolitics of everyday social contact and encounter" (959) are constituted and engaged with. That said, the "challenge of the possibility of living together" (Massey, 2005: 149, emphasis my own) provided by peer-sharing, suggests there is potential for challenging such hegemony and considering the benefits of difference. Consistent with Davidson and Milligan (2004), peer-shared living experiences were co-produced through 
friendships, encounters and the emotional and social networks performed in the flats. The participants spoke of mixed experiences of interacting with different genders, ages, ethnicities and nationalities in their flats. Some lived in very homogenous spaces, consisting of primarily young White, British, single-sex flats while others were more heterogeneous. Matias, Chen and Kristina, all international students, spoke of very different experiences of how diversity became inscribed into their peershared living spaces.

Chen had travelled from China to study a business degree at Plymouth University. Upon applying for accommodation she requested the option to live among nonChinese students as she wanted the opportunity to "learn how to adapt to living among different people" (Chen). This did not work out quite how she expected and she found herself placed in a flat with other female Chinese students:

"I was expecting halls to have more diversity, with different people from different cultures, countries. But actually my whole flat is Chinese. I was quite disappointed. I didn't know that before I arrived and I think they thought that because we were all Chinese we would all get along in the same flat." (Chen)

Nevertheless, while Chen was initially frustrated at not being placed among culturally different students, her mono-cultural experience presented certain opportunities to maintain her connections with home at a distance. Drawing on Baldasser's (2008) work on longing and missing, the cultural connections present in Chen's flat provided forms of emotional co-presence with her home that may not so easily have been achieved in other cultural configurations: 
"I suppose the good thing about living with other Chinese people is that you don't have to learn how to adapt to living among other people. [...] I mean it feels like we are back home in here, you know?" (Chen)

The ordering of space, the ease of sharing cultural norms and values, the subtle forms of cultural familiarity - such as food smells, phrases and dialects, co-produced alongside a sense of mutuality and friendship all helped contribute towards reproducing elements of a life "as it was before" (Boccagni, 2011: 9). This demonstrates the importance of being able to articulate culturally significant emotions for those living in/through mobility and how this assists with resolving feelings of absence through distance.

In contrast to Chen, Kristina, a Hungarian student living in one of Plymouth's most recent halls, had a more multicultural experience to Chen:

"In my flat, things are quite diverse. I am from Hungary and I have a flatmate who is Caribbean, and one from Qatar. It's really nice and our diversity has never been a source of problem in any way. It's nice to be around them and learn from them, particularly as culture often translates into food and that's really nice (laughs)." (Kristina)

Kristina's multicultural flat revealed very different opportunities to Chen in forming emotional connections with flatmates. While Chen's flat was steeped in cultural continuity, Kristina relished the prospect of sharing her cultural identity as well as experimenting with others' traditions. The opportunity to learn new cultural references through the materiality of the shared home was important to Christina and this appeared to temper the anxiety and awkwardness of being (quite literally) thrown-together. Place and mobility, in this context, are intensely active through the 
complex person-place relations that exist within the shared spaces, exposing what Conradson and McKay (2007) describe as the discernibly "'felt' dimensions of mobility" (169). Here, distanced social networks are imbued with emotional and cultural qualities that may both excite and challenge the sojourner (Brown, 2009). This was expressed through Kristina's flat's apparent willingness to draw their multiple identities together to help develop deeper emotional friendship networks that extended beyond the bubble of the flat and into their social lives:

"We get along so well, I'm really lucky. We aren't all the same but we complement each other. We support each other and have great conversations and our personalities complement each other. I play music and like to perform and my flatmates come and support me in the audience. I'm sure it was probably luck rather than anything else (laughs)." (Kristina)

While Kristina's comments acknowledge her 'luck' in encountering difference in what can be private and highly intimate living spaces, her remarks also emphasise the importance of emotional support in strengthening friendship bonds by resisting cultural homogeneities and encouraging opportunities to allow identities, experiences and habits to adapt and transform more spontaneously (Bunnell et al., 2012). Hence, to draw again on Massey (2005), both Chen and Kristina's experiences exhibit different senses of reflexivity about place, of familiarity and nostalgia but also senses of becoming and of the mysterious.

Finally, Matias, a 24-year-old Spanish postgraduate student living as a Resident Assistant (RA) in an older 1990s-built hall adjacent to campus spoke of having to work hard at encouraging his fellow flatmates to dismantle their preconceptions of him as being 'Other': 
"[...] it's like, the first day of term and everyone was moving in and they were like 'oh God, we've got an RA living with us - great'. I found that quite upsetting because I didn't choose to live with them, I was put here because I have a role in the uni y'know? It's all okay now though, I made sure we talked and got over it quickly." (Matias)

In contrast to both the cultural and gendered homogeneity in Chen's flat and Kristina's culturally heterogeneous living arrangements, Matias' experience problematises the benefits of investing emotional capital discussed earlier in the paper by highlighting the contrasting power relations that exist in shared spaces. Matias' cultural, gendered and aged identity, coupled with his 'structured' university role marked him out instantly as different amongst his peers. This chimes well with Moss and Richter's (2010) assertion that halls spaces may appear largely paradoxical, being simultaneously structured/unstructured, controlled/unregulated, public/private. Here, while the occupants of Matias' flat expressed initial disappointment at sharing with an RA - perhaps fearing they might not be able to behave in certain ways around him - he quickly ameliorated any perceived hostility by taking charge and encouraging discussion:

“Everyone has different views, and that's cool. I really can't be doing with friction so if people start to argue we have a kitchen meeting, we talk, we reassure that everything is alright for everyone." (Matias)

Themes of emotion and belonging punctuate all of this analysis, yet as Brickell (2012) argues, homes are increasingly problematic spaces that transcend metaphors of safety, comfort and familiarity. Similar to Seamon's 'place-ballets' (1979) whereby place is co-produced through movements, rest and encounters, Matias' experiences 
speak to these considerations, emphasising notions of the 'dynamic hierarchies' often present in student accommodation (Holton, 2016b). These may be founded upon tensions and conflict through which occupants draw upon various domestic knowledges and experiences to help position themselves within their respective households. Hence drawing emotions into this context reveals that, while emotions are free to be expressed, they sometimes need channelling in such ways as to galvanise, rather than exacerbate tensions among the household.

\section{Conclusion}

In conclusion, this paper has sought to examine how the complex interactions between people, spaces and emotions might affect living arrangements in peershared accommodation. As this analysis has shown, sojourners are not simply passive consumers of shared accommodation but are active agents in the production, negotiation and organisation of home within these spaces. This was observed in the dynamic ways through which the participants' emotions were articulated - be it through the organisation of the space, the arrangement of belongings or the expression of different communication networks. These peershared spaces could perhaps be termed paradoxical though - simultaneously spatially and temporally mimetic spaces, both placeless and imbued with memory, at once homely and institutionalised. Moreover, the complex diversities that exist within peer-shared accommodation may promote different hierarchical roles and encourage certain types of self-reflexivity among sharers. There was a real sense that the shared spaces here were more than simply places to reside during term-time but were genuine, active (and reactive) homes in which the sharers could work together to make place. The emotional work invested into peer-shared spaces through place- 
making certainly promoted communication and friendship and the place-making activities expressed by the participants were highly complex and tentative processes that may become inherently difficult due to the temporary and 'thrown-together' nature of peer-sharing. Indeed, the contrasting forms of social dependency expressed here challenge some of the cold classificatory understandings of shared living as being propelled by the Self (e.g. Giddens' (1991) notion of the 'pure relationship', whereby individuals enter into emotional relationships: "solely for whatever rewards that relationship as such can deliver" (6)) whilst ignoring the messy interactions that occur when people live among one another.

Beyond the perceived practicalities of these students' experiences of living together are the ways in which peer-shared living might extend (or at least muddy the waters of) understandings of emotional geographies by exposing how emotions might (co)produce the 'spaces in-between' (c.f. Pile, 2010), encounters and (im)material relations. While the analysis has exposed how peer-sharers might articulate the tacit or the explicit (either through communication, behaviours or activities), this paper has sought to examine how the participants' emotions contributed to, or were influenced by, the materiality of their living spaces. Robert's concerns over privacy, Chen's desire for cultural continuity, Scott and Ben's emotional place-making performances, all demonstrate how collectively emotions were literally inscribed into the accommodation itself through actions, reactions and interactions with and within the spaces. What this achieves is a more nuanced understanding of how the 'in-between spaces' of the student hall (kitchens, hallways etc.) can become distinctive indicators of the personality of the shared flat that moves beyond the privacy of the bedroom (Gosling et al., 2005). 


\section{Acknowledgements}

I particularly thank Scott Walker from Plymouth University's Residence Life for providing me access to my participants and for helping me develop the project. I would also like to thank Andrew Gorman-Murray and the anonymous reviewers for their insightful and constructive comments on an earlier version of the paper. Any errors of commission or omission remain entirely my own. This research did not receive any specific grant from funding agencies in the public, commercial, or not-for-profit sectors.

\section{References}

Amin, A. (2002). Ethnicity and the multicultural city: living with diversity. Environment and Planning A, 34(6), 959-980.

Anderson, K., and Smith, S.J. (2001). Editorial: emotional geographies. Transactions of the Institute of British Geographers, 26(1), 7-10.

Andersson, J., Sadgrove, J., and Valentine, G. (2012). Consuming campus:

geographies of encounter at a British university. Social and Cultural Geography, 13(5), 501-515.

Baldassar, L. (2008). Missing kin and longing to be together: emotions and the construction of co-presence in transnational relationships. Journal of intercultural studies, 29(3), 247-266.

Beck, U. (1992). Risk society: towards a new modernity. Sage: London.

Blakey, M. (1994). Student accommodation, in: S. Hazelgrove (Ed) The Student Experience. Buckingham: SRHE/Open University Press. 
Blunt, A. (2005). Cultural geography: cultural geographies of home. Progress in Human Geography, 29(4), 505-515.

Blunt, A., and Dowling, R. (2006). Home. Abingdon: Routledge.

Boccagni, P. (2011). Rethinking transnational studies: transnational ties and the transnationalism of everyday life, European Journal of Social Theory, DOI: 1368431011423600.

Boon, B. (2007). Working within the front-of-house/back-of-house boundary: room attendants in the hotel guest room space. Journal of Management and Organization, 13(2), 160-174.

Bourdieu, P. (1984). Distinction: A social critique of the judgement of taste. Harvard University Press: Cambridge MA.

Bowlby, S. (2011). Friendship, co-presence and care: neglected spaces. Social \& Cultural Geography, 12(6), 605-622.

Brickell, K. (2012). 'Mapping' and 'doing' critical geographies of home. Progress in Human Geography, 36(2), 225-244.

Brooks, R. (2007). Friends, peers and higher education. British Journal of Sociology of Education, 28(6), 693-707.

Brown, L. (2009). An ethnographic study of the friendship patterns of international students in England: An attempt to recreate home through conational interaction, International Journal of Educational Research, 48(3), 184-193. 
Brown, G. (2011). Emotional geographies of young people's aspirations for adult life. Children's Geographies, 9(1), 7-22.

Bunnell, T., Yea, S., Peake, L., Skelton, T., and Smith, M. (2012). Geographies of friendships. Progress in Human Geography, 36(4), 490-507.

Búriková, Z. (2006). The embarrassment of co-presence: Au pairs and their rooms. Home Cultures, 3(2), 99-122.

Christie, H., Munro. M., and Rettig, H. (2002). Accommodating students. Journal of Youth Studies, 5(2), 209-235.

Clapham, D., Mackie, P., Orford, S., Thomas, I., and Buckley, K. (2014). The housing pathways of young people in the UK. Environment and Planning A, 46(8), 2016-2031.

Clarke, N. (2005). Detailing transnational lives of the middle: British working holiday makers in Australia. Journal of Ethnic and Migration studies, 31(2), 307-322.

Clough, P.T. and Halley, J. (2007). The affective turn: theorizing the social. London: Duke University Press.

Conradson, D., and McKay, D. (2007). Translocal subjectivities: mobility, connection, emotion. Mobilities, 2(2), 167-174.

Davidson, J., Bondi, L., and Smith, M. (2007). Emotional geographies. Aldershot: Ashgate Publishing, Ltd.

Davidson, J., and Milligan, C. (2004). Embodying emotion sensing space: introducing emotional geographies. Social \& Cultural Geography, 5(4), 523-532. 
Dyck, I. (2005). Feminist geography, the 'everyday', and local-global relations: hidden spaces of place-making. The Canadian Geographer, 49(3), 233-243.

Elwood, S.A., and Martin, D.G. (2000). "Placing" interviews: location and scales of power in qualitative research. The Professional Geographer, 52(4), 649-657.

Fincher, R. and Shaw, K. (2009). The unintended segregation of transitional students in Central Melbourne, Environment and Planning A, 41(8), 1884-1902.

Giddens, A. (1991). Modernity and self-identity: Self and society in the late modern age. Cambridge: Polity Press.

Giorgi, S. and Fasulo, A. (2013). Transformative homes: squatting and furnishing as sociocultural projects. Home Cultures, 10(2), 111-133.

Goffman, E. (1959). The presentation of everyday life. New York: Anchor Books.

Gosling, S. D., Craik, K. H., Martin, N. R., and Pryor, M. R. (2005). Material attributes of personal living spaces. Home Cultures, 2(1), 51-87.

The Guardian. (2016). No straight people allowed: students share views on LGBTonly halls. https://www.theguardian.com/education/2016/may/16/no-straight-peopleallowed-students-share-views-on-lgbt-only-halls

Gustafson, P. (2001). Roots and routes exploring the relationship between place attachment and mobility. Environment and behavior, 33(5), 667-686.

Heath, S. (2004). Peer-shared households, quasi-communes and neo-tribes. Current Sociology, 52(2), 161-179. 
Heath, S., and Kenyon, L. (2001). Single young professionals and shared household living. Journal of Youth Studies, 4(1), 83-100.

Heidegger, M. (1977). Basic writings. London: Routledge.

Higher Education Statistics Agency (HESA). (2016). Free online statistics - students and qualifiers. http://www.hesa.ac.uk/content/view/1897/239/

Hockey, J., Penhale, B., and Sibley, D. (2007). Environments of memory: home space, later life and grief. In J. Davidson, L. Bondi, and M. Smith (Eds) Emotional geographies, (pp. 135-145). Aldershot: Ashgate.

Holdsworth, C. (2009). 'Going away to uni': mobility, modernity, and independence of English higher education students. Environment and Planning A, 41(8), 1849-1864.

Holton, M. (2016a). The geographies of UK university halls of residence: examining students' embodiment of social capital. Children's Geographies, 14(1), 63-76.

Holton, M. (2016b). Living together in student accommodation: performances, boundaries and homemaking. Area, 48(1), 57-63.

Holton, M., and Riley, M. (2014). Talking on the move: place-based interviewing with undergraduate students. Area, 46(1), 59-65

Holton, M., and Riley, M. (2016). Student geographies and homemaking: personal belonging (s) and identities. Social and Cultural Geography, 1-23.

Hopkins, P. (2011). Towards critical geographies of the university campus: understanding the contested experiences of Muslim students. Transactions of the Institute of British Geographers, 36(1), 157-169. 
Jarvis, H. (2011). Saving space, sharing time: integrated infrastructures of daily life in cohousing, Environment and Planning A, 43(3), 560-577.

Kenyon, E., and Heath, S. (2001). Choosing this life: narratives of choice amongst house sharers. Housing Studies, 16(5), 619-635.

McDowell, L. (2007). Spaces of the home: absence, presence, new connections and new anxieties. Home Cultures, 4(2), 129-146.

Massey, D. (2005). For space. London: SAGE Publications.

Moos, M. (2015). From gentrification to youthification? The increasing importance of young age in delineating high-density living. Urban Studies. DOI: 0042098015603292.

Morgan, D.G., and McDowell, L. (1979). Patterns of residence: costs and options in student housing. London: Society for Research into Higher Education.

Moss, D., and Richter, I. (2010). Understanding young people's transitions in university halls through space and time, Young, 18(2), 157-176.

Pile, S. (2010). Emotions and affect in recent human geography. Transactions of the Institute of British Geographers, 35(1), 5-20.

Pinney, C. (2004). 'Photos of the gods': the printed image and political struggle in India. London: Reaktion.

Reimer, S., and Leslie, D. (2004). Identity, consumption, and the home. Home Cultures, 1(2), 187-210. 
Robertson, S. (2016). Friendship networks and encounters in student-migrants' negotiations of translocal subjectivity. Urban Studies. DOI: 0042098016659617.

Rose, G. (2016). Visual methodologies: An introduction to researching with visual materials. London: Sage.

Seamon, D. (1979). A Geography of the Lifeworld. London: Croom Helm.

Silva, E.B. (2007). Gender, class, emotional capital and consumption in family life. In, E. Casey and L. Martens (Eds), Gender and consumption: domestic cultures and the commercialisation of everyday life (pp. 141-159). London: Routledge.

Silver, H. (2004). 'Residence' and 'accommodation' in higher education: abandoning a tradition. Journal of educational administration and history, 36(2), 123-133.

Smith, D.P. (2008) The politics of studentification and '(un)balanced' urban populations: lessons for gentrification and sustainable communities? Urban Studies, 45(12), 2541-2564.

Smith, D.P. (2012). The social and economic consequences of housing in multiple occupation (HMO) in UK coastal towns: geographies of segregation. Transactions of the Institute of British Geographers, 37(3), 461-476.

Smith, D.P., and Hubbard, P. (2014). The segregation of educated youth and dynamic geographies of studentification. Area, 46(1), 92-100.

Taulke-Johnson, R. (2010) Assertion, regulation and consent: gay students, flatmates, and the heterosexualisation of university accommodation space, Gender and Education, 22(4), 401-417. 
Urry, J. (2002). Mobility and proximity. Sociology, 36(2), 255-274.

Urry, J. (2003). Social networks, travel and talk. The British journal of sociology, 54(2), 155-175.

Valentine, G. (2008). Living with difference: reflections on geographies of encounter. Progress in human geography, 32(3), 323-337.

Van Criekingen, M. (2010). 'Gentrifying the re-urbanisation debate', not vice versa: the uneven socio-spatial implications of changing transitions to adulthood in Brussels. Population, space and place, 16(5), 381-394.

Watkins, H. (2006). Beauty queen, bulletin board and browser: rescripting the refrigerator. Gender, Place and Culture, 13(2), 143-152.

Wilkinson, E. (2014). Single people's geographies of home: intimacy and friendship beyond 'the family'. Environment and Planning A, 46(10), 2452-2468.

Williams, J. (2005) Designing neighbourhoods for social interaction: the case of cohousing, Journal of Urban Design, 10(2), 195-227. 

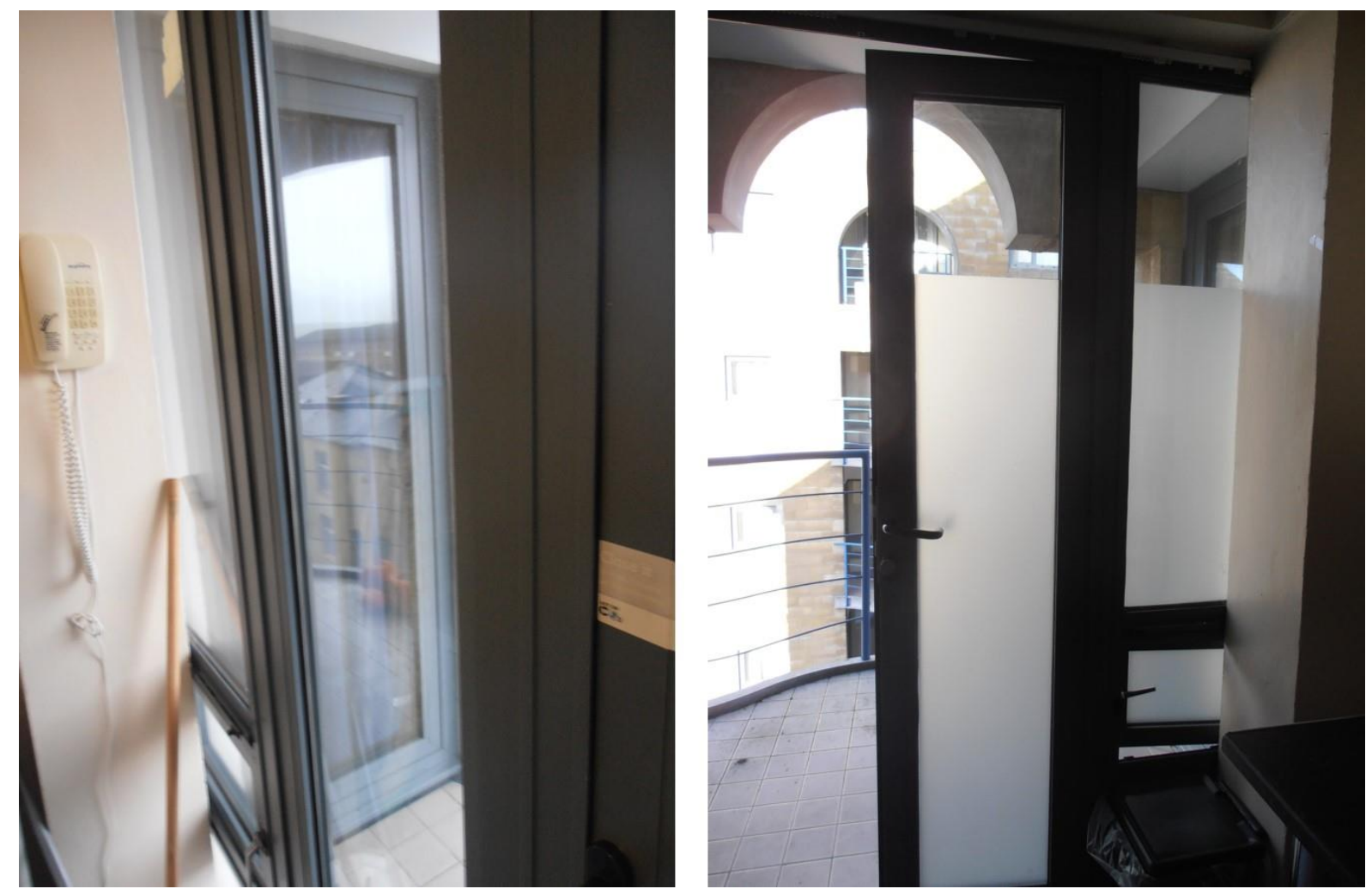

Figure 1: Unintentional invasions of privacy in Robert's bedroom (L) and modesty screening on Chen's balcony doors (R) (author's own photographs).
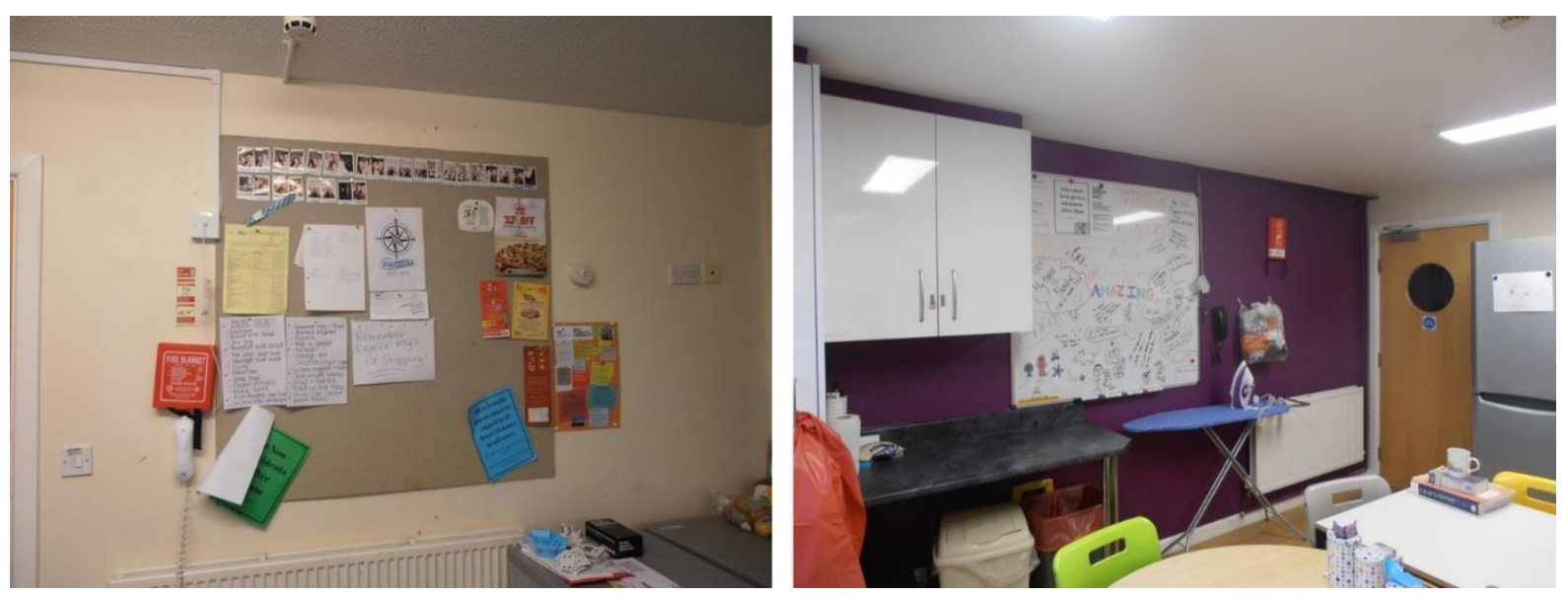

Figure 2: Displaying photographs on Peter's pin board (L) and doodles left by guests on Gary's whiteboard (R) (author's own photographs). 

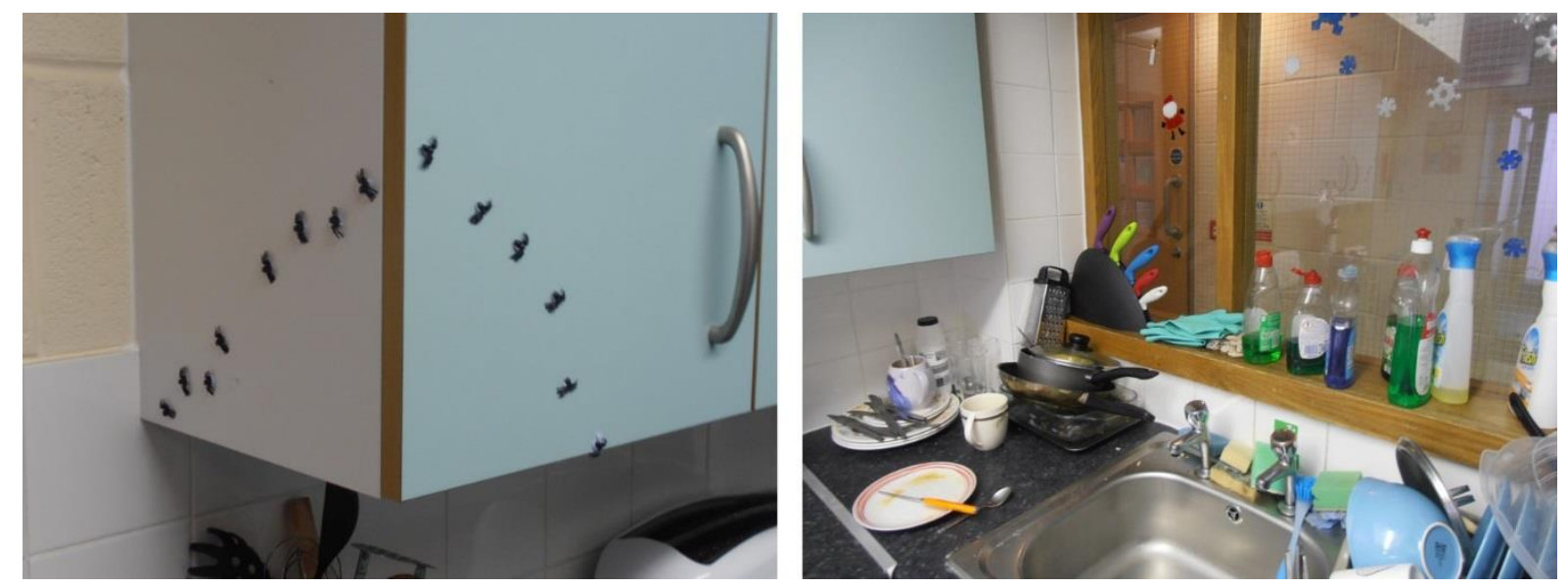

Figure 3: Personalisation and in-jokes in and around Ben's (L) and Scott's (R) kitchens (author's own photographs). 